\title{
MOTIVASI DAN DISIPLIN KERJA DAN KINERJA PEGAWAI DI DILI TIMOR LESTE
}

\author{
Tomas Augusto Correia', Meita Pragiwani² \\ Sekolah Tinggi Ilmu Ekonomi Indonesia \\ tomasaugusto.stei@gmail.com,ola_168@yahoo.com
}

\begin{abstract}
ABSTRAK
Universitas Dili berkedudukan di ibu kota Negara Republika Democratica Timor Leste dan berdiri pada tanggal 20 Mei 2002. Pada tahun 1998. Pasca referendum tanggal 30 agustus 1999 Timor Leste memasuki era baru menjadi sebuah Negara yang berdaulat. Pada tahun 2000 Timor Leste sudah menjadi sebuah Negara sendiri dengan identitas bahasa sendiri, selang berjalan dua tahun perkembangan jumlah mahasiswa semakin meningkat dan tuntutan masyarakat akan lembaga pendidikan tinggi demi membentuk sumber daya manusia yang berkualitas. Penelitian ini bertujuan untuk mengetahui pengaruh motivasi dan disiplin kerja terhadap kinerja pegawai di Universitas Dili Timor Leste. Hasil dari penelitian ini adalah Motivasi kerja dan disiplin kerja berpengaruh positf dan signifikan terhadap kinerja pegawai di Universitas Dili Timor Leste pada taraf nyata $\alpha=5 \%$. Besarnya pengaruh antara Motivasi dan Disiplin Kerja pada Kinerja di Universitas Dili adalah sebesar 62,9\%.
\end{abstract}

Kata Kunci : Motivasi, Disiplin Kerja, Kinerja Pegawai

\section{PENDAHULUAN}

Manusia merupakan sumber daya terpenting dalam suatu organisasi, instansi atau perusahaan, tanpa aspek manusia sulit kiranya instansi untuk mencapai misi dan tujuan yang telah ditetapkan. Sumber daya manusia merupakan satu -satunya sumber daya yang tidak bisa ditiru seperti memiliki akal, perasaan, keinginan, kemampuan, keterampilan, pengetahuan dan karya. Potensi sumber daya manusia tersebut berpengaruh terhadap upaya instansi dalam pencapaian tujuan. Instansi harus mempunyai sumber daya manusia yang berkualitas, sehingga mampu mengelola pegawai secara efektif dan efisien serta mampu mendukung pencapaian tujuan instansi (Malayu SP Hasibuan, 2014).

Kinerja pegawai merupakan hal penting yang harus di perhatikan karena kinerja pegawai mempengaruhi keberhasilan instansi tersebut dalam mencapai tujuannya. Kinerja pegawai yang baik dan memuaskan dapat menghasilkan produktivitas yang baik bagi instansi, sedangkan kinerja yang buruk dapat menghasilkan produktivitas yang rendah bagi instansi.

Motivasi merupakan suatu dorongan atau daya penggerak yang timbul dalam diri individu untuk melakukan sesuatu, motivasi timbul karena adanya rangsangan berupa kebutuhan baik materil mau pun non materil yang harus dipenuhi untuk mencapai kepuasan. Sebagaimana diungkapkan Samsudin (2010), "proses mempengaruhi atau mendorong dari luar terhadap seseorang atau kelompok kerja agar mereka mau melaksanakan sesuatu yang telah ditetapkan” Motivasi karyawan dapat dipengaruhi faktor minat, gaji yang diterima, kebutuhan akan rasa aman, hubungan antarpersonal dan kesempatan untuk bekerja”

Selain masalah motivasi, masalah lain yang terlihat di Universitas Dili Timor Leste dalam meningkatkan kinerja karyawan yaitu kedisiplinan karyawan. Kedisiplin merupakan sikap mental yang tercemin dalam perbuatan tingkah laku karyawan berupa kepatuhan atau ketaatan terhadap peraturan perusahaan. Peningkatan disiplin menjadi bagian yang penting dalam manajemen sumber daya manusia, sebagai faktor penting dalam peningkatan produktivitas. Permasalahan yang muncul adalah bagaimanakah usaha yang dilakukan untuk meningkatkan disiplin karyawan.

\section{Tujuan dari penelitian ini adalah :}

1. Untuk mengetahui pengaruh motivasi pegawai Karyawan terhadap Kinerja 
Pegawai di Universitas Dili Timor Leste

2. Untuk mengetahui pengaruh disiplin kerja pegawai Karyawan terhadap Kinerja Pegawai di Universitas Dili Timor Leste?

3. Untuk mengetahui pengaruh motivasi dan disiplin kerja terhadap kinerja pegawai di Universitas Dili Timor Leste?

\section{TINJAUAN PUSTAKA}

\section{Motivasi Kerja}

Menurut Hasibuan Malayu S.P dalam Sunyoto Danang (2012) motivasi adalah suatu perangsang keinginan daya gerak kemauan bekerja seseorang, setiap motif mempunyai tujuan tertentu yang ingin dicapai.

Menurut Asa'ad dalam pasalog Harbani (2010) motivasi adalah sesuatu yang menimbulkan semangat atau dorongan kerja.

Menurut A. A. Prabu Mangkunegara (2009), berpendapat bahwa Motivasi adalah kondisi yang menggerakan pegawai agar mampu mencapai tujuan dari motifnya

\section{Faktor-Faktor Yang Mempengaruhi Motivasi Kerja}

Faktor-faktor yang mempengaruhi motivasi kerja menurut Sustermeister dalam Djatmiko, Yayat Hayati (2002) yaitu:

1. Kondisi lingkungan kerja

2. Kondisi social lingkungan kerja

3. Keterpenuhan kebutuhan dasar individu

Sedangkan menurut Pasualang, Harbani (2010) faktor-faktor yang mempengaruhi motivasi kerja yaitu:
1) Faktor Eksternal
a) Kepemimpinan
b) Lingkungan kerja yang menyenangkan
c) Komposisi yang memadai
d) Adanya penghargaan akan prestasi
e) Status dan tanggung jawab
2) Faktor Internal
a) Kematangan pribadi
b) Tingkat pendidikan
c) Keinginan dan harapan pribadi
d) Kebutuhan terpenuhi
e) Kelemahan dan keborosan
f) Kepuasan kerja

Berdasarkan pendapat di atas bisa disimpulkan bahwa yang mempengaruhi motivasi kerja yaitu faktor eksteren dan interen. Faktor eksteren yang mempengaruhi motivasi kerja kondisi linkungan kerja, kepemimpinan, status dan jabatan. Faktor interen kebutuhan terpenuhi, tingkat pendidikan dan kepuasan kerja.

\section{Disiplin Kerja}

Menurut Mangkunegara (2013), disiplin kerja diartikan sebagai pelaksanaan manajemen untuk memperteguh pedomanpedoman organisasi. Kadang-kadang, perilaku pekerja dalam organisasi menjadi sangat mengganggu sehingga berdampak dengan kinerja yang menurun.

Menurut Hasibun (2015), kedisiplinan adalah kunci keberhasilan suatu perusahaan dalam mencapai tujuan tujuannya. Disiplin merupakan fungsi penting dalam sebuah organisasi karena semakin baik kedisiplinan karyawan, semakin tinggi prestasi kerja yang dapat dicapainya. Sebaliknya, tanpa disiplin, sulit bagi organisasi perusahaan mencapai hasil yang optimal. Kedisiplinan harus diterapkan dalam suatu perusahaan karena akan berdampak terhadap kinerja karyawan, sehingga mempengaruhi kesuksesan dan keberhasilan dari perusahaan.

\section{Kinerja}

Definisi Kinerja Menurut Kuswadi (2004) kinerja adalah hasil kerja yang dapat dicapai seseorang atau sekelompok orang dalam organisasi, sesuai dengan wewenang dan tanggung jawab masing-masing dalam rangka untuk mencapai tujuan organisasi sesuai dengan aturan yang berlaku. Kinerja (performance) berarti pelaksanaan kerja, pencapaian kerja atau hasil kerja dan penampilan kerja. Kinerja dipengaruhi oleh faktor faktor antara lain kepuasan karyawan, kemampuan ka 20

\section{Faktor-Faktor Yang Mempengaruhi Kinerja}

Menurut Kuswadi (2004), terdapat 5 faktor yang mempengaruhi kinerja, antara lain:

1) Faktor Kantor Faktor kantor merupakan sarana yang menunjang seorang karyawan untuk melakukan aktivitas kerja dengan baik. Apabila perusahaan tidak dapat memberikan fasilitas yang memadai, tentu saja hal ini akan menurunkan kinerja kerja karyawan. 
2) Lingkungan Kerja Lingkungan kerja merupakan faktor yang sangat penting untuk di perhatikan karena hamper $80 \%$ karyawan resign jika lingkungan kerja mereka tidak baik.

3) Prioritas Kerja Memberikan prioritas kerja yang baik akan membuat pegawai mengerjakan pekerjaan satu demi satu dengan timeline yang telah ditentukan.

4) Supportive Boss Sebagai seorang atasan, berikan dukungan kepada para karyawan untuk mengemukakan pendapat dan ideide baru pada saat meeting.

5) Bonus Sebagian besar karyawan akan bekerja dengan senang hati apabila pekerjaan yang mereka kerjakan dihargai oleh perusahaan dan memberikan bonus atas apa yang telah mereka kerjakan
Menurut Kuswadi (2004) ada beberapa cara untuk meningkatkan kinerja karyawan, antara lain yaitu :

a. Gaji yang Baik

b. Rekan Kerja yang Kompak

c. Suasana Lingkungan Kerja yang Nyaman

d. Penghargaan terhadap Pekerjaan

e. Kesempatan untuk Maju

f. Pimpinan yang Adil Dan Bijaksana

\section{Hipotesis 1 :}

Disiplin kerja berpengaruh positif terhadap kinerja karyawan Universitas Dilli Timor Leste Hipotesis 2 :

Motivasi kerja berpengaruh positif terhadap kinerja karyawan Universitas Dilli Timor Leste. Hipotesis 3:

Disiplin kerja dan motivasi kerja mempunyai pengaruh positif yang signifikan terhadap kinerja karyawan Universitas Dilli Timor Leste

\section{Kerangka Penelitian}

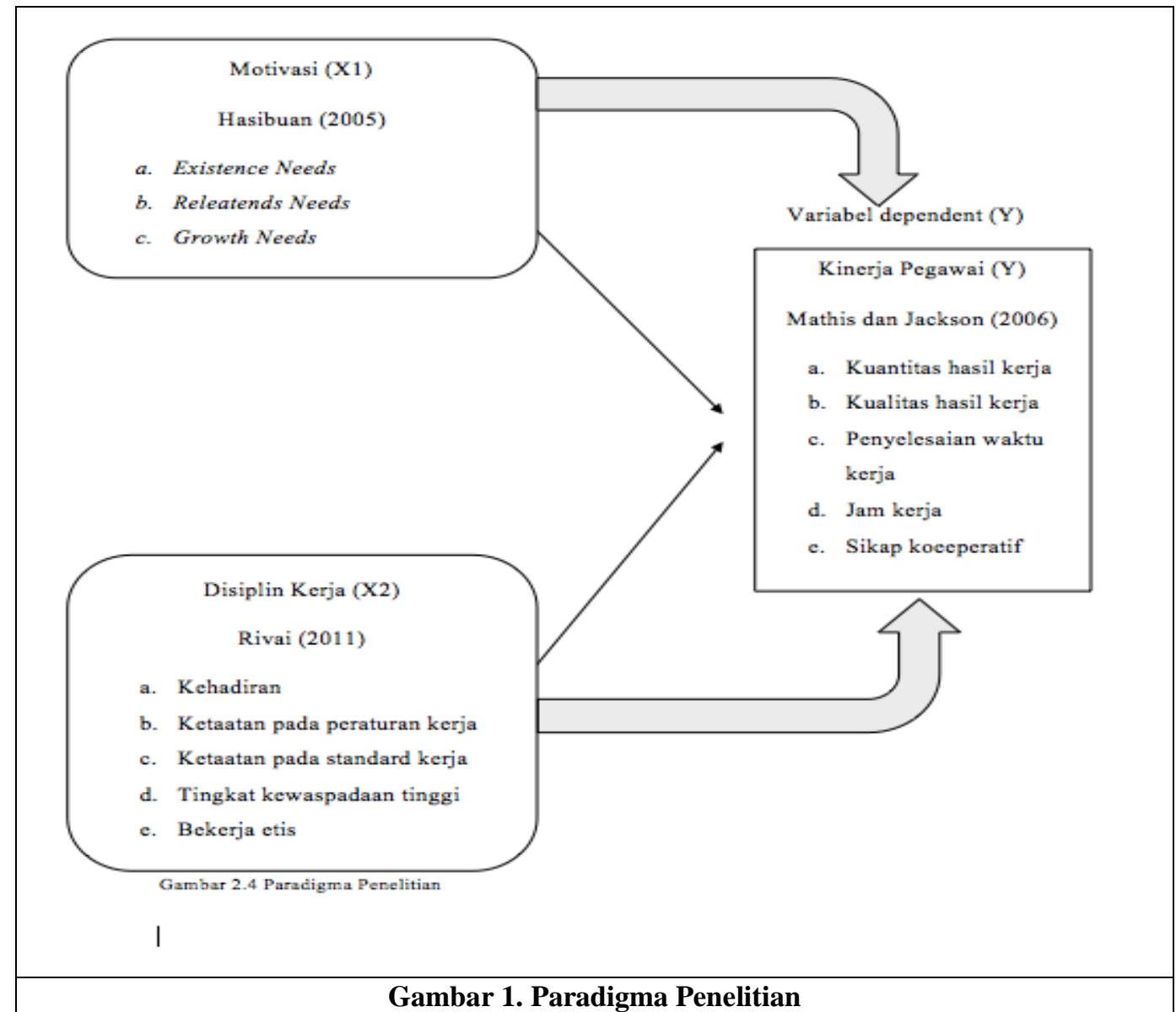

Setiap karyawan harus memiliki disiplin kerja didalam organisasi atau perusahaannya, seperti mematuhi peraturan tertulis maupun tidak tertulis yang telah di 
tetapkan oleh perusahaan karena hal tersebut dapat menciptakan lingkungan kerja yang kondusif dan harmonis sehingga akan memberikan dampak yang positif terhadap kinerja karyawannya.

Berdasarkan hasil penelitian Ariana (2013) disebutkan bahwa perusahaan bisa lebih memperhatikan kemampuan karyawan, balas jasa terhadap karyawan, sanksi terhadap pelanggaran disiplin, pengawasan yang lebih ketat dalam upaya meningkatkan atau memperbaiki kinerja karyawan. Hal-hal tersebut membuktikan bahwa disiplin kerja merupakan faktor penting dalam meningkatkan kinerjakaryawan. Dengan adanya disiplin kerja yang baik dari karyawan seperti datang tepat waktu, melaksanakan pekerjaan sesuai dengan apa yang telah ditetapkan oleh perusahaan, mentaati peraturan perusahaan maka akan dapat meningkatkan kinerja dari karyawan tersebut sehingga target perusahaan akan tercapai.

\section{METODOLOGI}

Penelitian ini dilakukan di Universitas Dili Timor Leste yang berlokasi di jalan Avenida Bispo de mediros, Dili Timor Leste. Sedangkan waktu yang ditempuh untuk penelitian ini dimulai dari penyusunan proposal penelitian sampai penyerahan versi akhir laporan penelitian yang diperkirakan selama enam bulan, terhitung mulai dari bulan September 2018 sampai dengan bulan Februari 2019.

Untuk menentukan jumlah sampel dalam penelitian ini digunakan rumus Slovin dengan tingkat kesalahan yang masih bias di tolelir sebagai berikut $\mathrm{n}=\mathrm{N} /(1+\mathrm{Ne} 2)$

Model penelitan ini adalah : keterangan :

$\mathrm{n}$ = jumlah sampel

$\mathrm{N}=$ jumlah Populasi

$\mathrm{e}=$ presentase kelonggaran ketidaktelitian karena kesalahan pengambilan sampel yang dapat di tolerir atau yang diinginkan sebesar $10 \%$ berdasarkan rumus tersebut maka dapat di ketahui sampel sebesar

$\mathrm{n}=267 / 1+((267(0,1) 2)=72,75 / 73$

Setelah dilakukan perhitungan dengan rumus slovin maka jumlah sampel yang digunakan dalam penelitian ini sebanyak 73 responden

Metoda pengumpulan data yang digunakan dalam penelitian ini adalah :

1. Riset pustaka dilakukan berdasarkan buku yang berhubungan dengan masalah yang akan dibahas untuk mendapatkan teori-teori yang dapat dijadikan pedoman dalam penelitian ini.

2. Penelitian lapangan Penelitian lapangan adalah penelitian yang dilakukan untuk mendapatkan data secara langsung dari perusahaan atau tempat obyek penelitian melalui cara cara seperti Observasi dan Kuesioner

\section{DISKUSI DAN PEMBAHASAN}

Hasil dari data yang telah disebarkan selama proses penelitian dijelaskan sebagai berikut;

1. Hasil kuesioner dibagikan kepada seluruh responden sebanyak 73 (tujuh puluh tiga)

2. Hasil kuesioner kemudian di ubah formatnya dengan MSI (Succesive Interval).

3. Hasil pengolahan MSI akan diolah dengan SPSS.

$\hat{\mathbf{Y}}=-0,029+0,337 \times 1+0,745 \times 2+e$

Model Summahy

\begin{tabular}{|c|c|c|c|c|c|c|c|c|c|c|}
\hline \multirow[b]{2}{*}{ Model } & \multirow[b]{2}{*}{$\mathrm{R}$} & \multirow[b]{2}{*}{ R Square } & \multirow[b]{2}{*}{$\begin{array}{l}\text { Adjusted } \\
\text { R Square }\end{array}$} & \multirow[b]{2}{*}{$\begin{array}{l}\text { Std. Error of } \\
\text { the Estimate }\end{array}$} & \multicolumn{5}{|c|}{ Change Statistics } & \multirow[b]{2}{*}{$\begin{array}{l}\text { Durbin- } \\
\text { Watson }\end{array}$} \\
\hline & & & & & $\begin{array}{c}\text { R Square } \\
\text { Change }\end{array}$ & F Change & df1 & $\mathrm{df} 2$ & Sig. F Change & \\
\hline 1 & $.829^{\mathrm{a}}$ & .687 & .678 & .35410 & .687 & 76.717 & 2 & 70 & .000 & 1.951 \\
\hline
\end{tabular}

a. Predictors: (Constant), $\mathrm{X}, \mathrm{X} 1$

b. Dependent Variable: $Y$

Besarnya nilai adjusted $\mathrm{R}$ Square adalah 0,678 atau $67,8 \%$ variasi dari kinerja pegawai dapat dijelaskan oleh variasi dari motivasi kerja dan disiplin kerja sedangkan sisanya dijelaskan oleh faktor lain yang tidak diteliti dalam penelitian ini. 
Hasil penelitian menunjukan bahwa terdapat pengaruh yang signifikan motivasi kerja terhdap kinerja pegawai. Hal ini berarti bahwa semakin baik tingkat motivasi kerja akan semakin meningkatkan kinerja pegawai di Universitas Dili. Hasil ini sesuai dengan penelitian yang dilakukan oleh Suparno dan Sudarwati (2011) yang menyatakan bahwa motivasi kerja merupakan salah satu kunci dari meningkatkan performa kinerja daripada pegawai.

\section{KESIMPULAN DAN SARAN}

\section{Kesimpulan}

1. Motivasi kerja berpengaruh positf dan signifikan terhadap kinerja pegawai di Umiversitas Dili Timor Leste pada taraf nyata $\alpha=5 \%$. Hal ini menunjukkan bahwa indikator motivasi telah dilakukan di Universitas Dili. Besarnya hubungan antara Motivasi dan Kinerja adalah sebesar 0.682 yang masuk kategori sangat erat.

2. Disiplin kerja berpengaruh positf dan signifikan terhadap kinerja pegawai di Umiversitas Dili Timor Leste pada taraf nyata $\alpha=5 \%$. Besarnya hubungan antara disiplin kerja dan kinerja adalah sebesar 0.796 yang masuk dalam kategori erat.

3. Motivasi kerja dan disiplin kerja berpengaruh positf dan signifikan terhadap kinerja pegawai di Universitas Dili Timor Leste pada taraf nyata $\alpha=5 \%$. Besarnya pengaruh antara Motivasi dan Disiplin Kerja pada Kinerja di Universitas Dili adalah sebesar 62,9\%

Saran

\section{Bagi Universitas Dili}

Berdasarkan hasil penelitian menunjukan kinerja pegawai sudah baik di lingkungan kampus dan diharapkan dapat terus dipertahankan secara berkelanjutan dan pihah manajemen kampus selalu mengidentifikasi kebutuhan-kebutuhan yang harus didaptkan oleh para pegawai agar mereka terus termotivasi dalam bekerja serta mengupdate secara terus menerus mengenai standard operasional kerja sehingga tingkat kedisiplinan kerja dari pegawai baik dosen maupun staff terus terjaga.

Penggunaan evaluasi kepada peningkatan motivasi dan disiplin kerja yang lebih terintegrasi dapat dimasukkan dalam rencana pengembangan sumberdaya manusia di Universitas Dili.

\section{Bagi penelitian selanjutnya}

Diharapkan pada penelitian selanjutnya untuk menggunakan jumlah sampel lebih banyak dan lebih luas, serta menambah variabel independent lainnya agar dapat menjawab faktor-faktor apa saja yang mempengaruhi daripada kinerja pegawai seperti kepemimpinan atau lingkungan kerja karena peneliti menyadari bahwa kurang maksimal dalam melakukan riset dikarenakan faktor waktu yang tidak cukup dan memadai.

\section{Daftar Pustaka}

A.A. Anwar Prabu Mangkunegara. 2009. Manajemen Sumber Daya Manusia. Bandung : Remaja Rosdakarya

Hasibuan 2005. Manajemen Sumber Daya Manusia Jakarta : Bumi Aksara

Hasibuan, Malayu S.P. 2014. Manajemen Sumber Daya Manusia (Edisi Revisi) Jakarta : Bumi Aksara

Hasibuan 2015. Manajemen Sumber Daya Manusia (Edisi Revisi) Jakarta : Bumi Aksara

Kuswadi 2004. Cara Mengukur Kepuasan Karyawan. Jakarta : Elex Media

Mangkunegara. 2013. Manajemen Sumber Daya Manusia. Bandung : Remaja Rosdakarya

Pasalog, Harbani. 2010. Teori Administrasi Publik. Bandung : Alfabeta

Samsudin, Sadili. 2010. Manajemen Sumber Daya Manusia. Bandung : Pustaka Setia

Sunyoto Danang. 2012. Manajemen Sumber Daya Manusia. Yogyakarta : CAPS

Sutrisno, Edy 2014 Manajemen Sumber Daya Manusia Edisi 1 Cetakan keempat Jakarta : Prenada Media Group

Singodimedjo 2010 Manajemen Sumber Daya Manusia Pengaruh Disiplin Kerja Terhadap Prestasi Kerja Jakarta : Kencana. 